\title{
Non-traumatic and non-drug-induced rhabdomyolysis
}

Genovefa Kolovou ${ }^{1}$, Philip Cokkinos ${ }^{1}$, Helen Bilianou ${ }^{2}$, Vana Kolovou ${ }^{1,3}$, Niki Katsiki ${ }^{4}$, Sophie Mavrogeni ${ }^{1}$

${ }^{1}$ Cardiology Department, Onassis Cardiac Surgery Center, Athens, Greece ${ }^{2}$ Cardiology Department, Tzanio Hospital, Piraeus, Greece

${ }^{3}$ Molecular Immunology Laboratory, Onassis Cardiac Surgery Center, Athens, Greece

${ }^{4}$ First Department of Internal Medicine, Division of Endocrinology-Metabolism,

Diabetes Center, AHEPA University Hospital, Thessaloniki, Greece

Submitted: 18 August 2019

Accepted: 10 October 2019

Arch Med Sci Atheroscler Dis 2019; 4: e252-e263

DOI: https://doi.org/10.5114/amsad.2019.90152

Copyright (c) 2019 Termedia \& Banach

\begin{abstract}
Rhabdomyolysis (RM), a fortunately rare disease of the striated muscle cells, is a complication of non-traumatic (congenital (glycogen storage disease, discrete mitochondrial myopathies and various muscular dystrophies) or acquired (alcoholic myopathy, systemic diseases, arterial occlusion, viral illness or bacterial sepsis)) and traumatic conditions. Additionally, RM can occur in some individuals under specific circumstances such as toxic substance use and illicit drug abuse. Lipid-lowering drugs in particular are capable of causing RM. This comprehensive review will focus on non-traumatic and nondrug-induced RM. Moreover, the pathology of RM, its clinical manifestation and biochemical effects, and finally its management will be discussed.
\end{abstract}

Key words: rhabdomyolysis, myoglobulin, dystrophy, myopathy.

\section{Introduction}

The term "rhabdomyolysis" (RM) first entered PubMed in 1959 [1], although its first clinical description appeared more than a thousand years ago [2]. Fortunately a rare disease, it usually presents as a complication of non-traumatic (congenital (glycogen storage diseases, mitochondrial myopathies and muscular dystrophies) or acquired (alcoholic myopathy, systemic disease, artery occlusion, viral or bacterial illness)) and traumatic conditions. Additionally, RM may occur in some individuals under specific circumstances such as toxic substance use and illicit drug abuse. Lipid-lowering drugs may also cause RM [3].

Recognizing underlying disorders presenting with RM, particularly genetic disorders, is a diagnostic challenge: these diseases are uncommon and present with a wide range of symptoms. Despite this challenge, timely diagnosis and appropriate laboratory evaluation are crucial for the prevention of new episodes [4]. Early identification of RM is especially crucial for the prevention of acute kidney disease (AKD) as RM is a severe, potentially life-threatening condition with a mortality rate of $\sim 10 \%$ which is even higher in patients with AKD [5]. Clinically, RM presents with muscle aches and weakness, oedema and dark-red urine discoloration. Many patients experience only one episode of RM; patients with more than one episode, additionally to the above-described symptoms, complain of exercise intolerance and fatigue and may have

\author{
Corresponding author: \\ Philip Cokkinos MD, FRCP, \\ FESC \\ Cardiology Division \\ Onassis Cardiac \\ Surgery Centre \\ 356 Sygrou Avenue \\ 17674 Athens, Greece \\ Phone: +30 2109493549 \\ Fax: +30 2109493336 \\ E-mail: philipcokkinos@ \\ yahoo.com
}


a positive family history for myopathy. Typically, in $\mathrm{RM}$, the increase of serum creatine kinase (CK) is $>10$ times the normal upper limit (ULN). If AKD is present then creatinine elevation, red urine discoloration [6], oliguria (rarely anuria) and electrolyte abnormalities are observed [7]. However, the clinical symptoms are often non-specific, and red-coloured urine is usually the first indication of RM [8].

$\mathrm{RM}$ is defined as necrosis of muscle cells which leads to: 1) leakage of intracellular substances to the extracellular fluid and bloodstream and 2) uncontrolled entry of extracellular substances into damaged muscle cells, principally calcium. Both reactions can cause various systemic complications [9]. This review will focus on non-traumatic and non-drug-induced RM.

\section{Rhabdomyolysis in genetic disorders}

RM can occur in patients with underlying genetic conditions such as glycogen storage diseases (GSDs), mitochondrial myopathies, and muscular dystrophies, which are a diverse group of ailments resulting in progressive muscle atrophy and weakness [10]. In most cases the diagnosis of congenital myopathy may be obvious because the affected individual has already some level of muscle weakness, although exercise-induced cramps may be the only presenting symptoms. Below we briefly analyze the examples of muscle myopathies which more frequently than other GSDs induce RM.

\section{Glycogen storage disease}

Glycogen is a form of carbohydrate and in humans is stored in skeletal muscle $(\sim 500 \mathrm{~g})$ and liver ( $100 \mathrm{~g})$ cells [11]. Glycogen storage is controlled by feedback-mediated inhibition of glycogen synthase to prevent exaggerated glycogen accumulation. There are more than 13 types of GSD, which are classified with Roman numerals and, if the name of the person who first reported it is known, the disease is called accordingly [11].

\section{McArdle disease (GSD-V)}

GSD-V is the most common disorder of muscle glycogenesis and is caused by mutations (autosomal recessive) in the PYGM gene which encodes glycogen phosphorylase $[12,13]$ resulting in an inability of converting muscle glycogen into glucose-1-phosphate. This produces glycogen accumulation within skeletal muscle cells. Typically, McArdle disease presents in the first two decades of life with exercise intolerance and muscle cramps (occurring within the first few minutes of physical effort), episodes of RM, and the second-wind phenomenon [12, 13]. Additional clinical features may involve muscle hypertrophy and permanent muscle weakness, mainly shoulder girdle and axial [13-15]. De Stefano et al. [16] observed a decrease in the rate of oxidative phosphorylation in muscle cells of patients with GSD-V due to reduced delivery of glycogen phosphorylase to their mitochondria and impaired anaerobic glycolysis. Moreover, subjects with McArdle disease frequently develop insulin resistance which leads to impaired glucose uptake, impaired glycogen production, and alterations in fuel oxidation. During exercise, a rise in lactate and ammonia occurs, causing fatigue and exercise intolerance even in the first minutes of physical effort and a disproportional increase in heart rate. Notably, insulin sensitivity decreases with age and this may partially explain the disease's late onset in some cases [17]. Moreover, Haller et al. [18] showed that in patients with GSD-V the $\mathrm{Na}^{+}-\mathrm{K}^{+}$pump may be impaired, and this further limits exercise capacity by inducing a failure of skeletal muscle cell membrane excitability.

RM may present in approximately $50 \%$ of GSD-V patients but it is likely that only a few develop AKD. Park et al. reported recurrent episodes of RM after seizures in a Korean patient with PYGM mutations [19].

Stimulators of RM in patients with GSD-V include the continuation of physical activity despite symptoms, intense exertion [20, 21], viral infections and seizures $[19,22]$.

\section{Tarui disease (GSD-VII)}

Tarui disease is caused by a mutation (autosomal recessive) in the PFKM gene encoding phosphofructokinase (PFK) which catalyses the conversion of fructose-6-phosphate to fructose-1.6-diphosphate. PFK deficiency causes myopathy and/or haemolysis and may be asymptomatic. Four clinical subclasses of Tarui disease have been identified: classical, infantile, late-onset, and haemolytic [23]. Patients with the classical presentation complain of muscle cramps and aches, physical intolerance, accompanied by nausea and vomiting. Jaundice, elevated CK levels, hyperuricaemia, and increased serum bilirubin can also be seen. Early presentation of Tarui disease may manifest as "floppy babies", arthrogryposis and mental retardation. Infants affected with Tarui disease may die within the first year of their lives. Late onset presents usually in the fifth decade and leads to severe disability. The haemolytic form features haemolytic anaemia. The combination of haemolytic anaemia and myopathy should raise the suspicion of GSD-VII [24, 25].

Stimulators of RM in patients with GSD-VII include intense exercise, particularly isometric muscle contraction [25]. 


\section{GSD-IX}

GSD-IX (also called GSD-IXb or GSD-IXd) is caused by deficiency of the phosphorylase kinase (PhK) which is encoded by the PHKB gene [26]. $\mathrm{PhK}$ is involved in glycogen [27]. There are two types of PhK deficiency, liver PhK and muscle PhK. The former is characterized by exercise intolerance, myalgia, muscle cramps, progressive muscle weakness and episodes of RM.

Stimulators of RM in patients with GSD-IX: exaggerated physical effort.

\section{GSD-X}

GSD-X is caused by a mutation (autosomal recessive) in the $P G A M 2$ gene and is characterized by a reduction of phosphoglycerate mutase (PGAM). Usually, symptoms do not present in daily activities but after exaggerated physical effort with muscle pains, myoglobinuria and RM.

Stimulators of RM in patients with GSD-X: exaggerated physical effort [28-31].

\section{GSD-XII}

GSD-XII, or aldolase A, deficiency is caused by mutations (autosomal recessive) in the ALDOA gene and is characterized by lack of production of dihydroxyacetone phosphate and glyceraldehyde 3-phosphate from fructose 1,6-bisphosphate, due to the deficiency of the aldolase A isoform [32, 33]. It usually affects muscle cells and erythrocytes. Patients may present with haemolytic anaemia, muscle pains, exercise intolerance, fatigue and episodes of RM [33-35], which can appear in the first months of life [32, 34].

Stimulators of RM in patients with GSD-XII include fever and infections [32-36].

\section{Mitochondrial myopathies}

Impaired oxidative phosphorylation and reduction of adenosine triphosphate (ATP) production are the two main defects of mitochondrial diseases [37]. These disorders belong to the most severe inborn metabolic diseases, which may be present even in newborns and young children. The enzymes involved in respiratory chain complexes and ATP synthase are encoded by maternally transmitted mitochondrial DNA (mtDNA) and nuclear DNA ( $n D N A)$. Thus, pathogenic mutations can therefore reside in both nuclear and mitochondrial genomes. According to mitochondrial myopathies [38-40], fortunately episodes of RM are infrequent and only a few examples will be analysed below. Generally, mitochondrial myopathy can be classified into 5 groups: 1) mitochondrial myopathy, encephalopathy, lactic acidosis, and stroke-like episodes (MELAS) [38], 2) myoclonus epilepsy associated with ragged-red fibres (MERRF) [41,
42], 3) Kearns-Sayre syndrome (KISS) [43], 4) chronic progressive external ophthalmoplegia (CPEO) [44], and 5) neurogenic weakness with ataxia and retinitis pigmentosa (NARP) $[45,46]$.

The stimulators leading to RM in patients with MELAS, MERRF, KISS, CPEO or NARP syndromes are similar and include strenuous physical exertion, fever and infection $[47,48]$.

\section{MELAS syndrome}

The MELAS syndrome was first described by HW Koenigsberg [49] but the name was given in 1984 by Pavlakis et al. [50]. Approximately $80 \%$ of affected individuals are carriers of the mitochondrial transporter (tRNA) m.3243A>G gene. The frequency of this mutation in the general population is about $1 / 15,000$ births. Affected individuals may develop diabetes mellitus, deafness, encephalopathy, seizers, stroke-like episodes, partially reversible blindness, short stature and exercise intolerance $[38,47,48]$. Nearly $22 \%$ of affected individuals will die before the age of 18 .

\section{MERRF syndrome}

The MERRF syndrome is a multisystem disorder characterized by myoclonus (often the first presentation) [41, 42]. The mtDNA gene MT-TK encoding tRNA ${ }^{\text {Lys }}$ is the gene most commonly associated with MERRF and is maternally transmitted. Affected individuals may also present with generalized epilepsy, ataxia, sensorineural hearing loss, myopathy, peripheral neuropathy, dementia, short stature, exercise intolerance, and optic atrophy. Ragged-red fibres (RRF) are found in muscle biopsy or an mtDNA pathogenic variant identified. Less frequent clinical features include cardiomyopathy, pigmentary retinopathy, pyramidal signs, ophthalmoparesis and lipomatosis [41, 42].

\section{KISS syndrome}

The KISS syndrome has a typical onset before the age of 20 and manifests with progressive external ophthalmoplegia, pigmentary retinopathy, and cardiac conduction block, hyperproteinorrhachia or ataxia [43].

\section{CPEO}

Patients with CPEO usually present with progressive paralysis of the external eye muscles resulting in limited sideways or upwards gaze, muscle fatigue and weakness, exercise intolerance and psychiatric disorders [44].

\section{NARP}

NARP was first described by Holt et al. [51] and presents with ptosis, external ophthalmoplegia, 
proximal myopathy and exercise intolerance, cardiomyopathy, sensorineural deafness, optic atrophy, pigmentary retinopathy, and diabetes mellitus.

\section{Muscular dystrophies}

\section{DMD}

Mutations of the dystrophin gene are the cause of 2 harmful and still incurable diseases, Duchenne (DMD) Becker (BMD) muscular dystrophies [52, 53]. Dystrophinopathies are sex-linked disorders. The lack of dystrophin destabilizes the muscle membrane, leading to clinical features of delayed motor development, calf hypertrophy, joint contractures, and progressive muscle weakness leading to scoliosis, cardiomyopathy, respiratory insufficiency, severe physical disability and reduced life expectancy, with death occurring before the third or fourth decade of life [52, 54-59]. DMD affects $1 / 3,500-5,000$ live-born males; it is the most common type of muscular dystrophy in childhood [57, 58]. Dystrophin is an important part of the dystrophin-associated glycoprotein complex, is associated with other cytoskeletal proteins [60], and is essential for cell survival via its transmembrane signalling function and modulation of vasomotor response to physical activity [61].

\section{Other genetic disorders}

\section{Carnitine palmitoyltransferase deficiency II (CPTII)}

Other genetic (autosomal recessive) metabolic disorders which are associated with RM include CPTII deficiency [62-65], which affects adolescents and young adults and is characterized by recurrent myoglobinuria, muscle aches, and stiffness induced by exercise, fasting, infection, exposure to cold and stress. The condition may be silent until the first episode of RM.

\section{Malignant hyperthermia (MH)}

A genetic disorder which manifests as a hypermetabolic response to potent inhalation agents (halothane, isoflurane, sevoflurane, desflurane), the depolarizing muscle relaxant succinylcholine, and to stressors such as strenuous exercise and heat [66-68].

The two genes that have been definitively associated with $\mathrm{MH}$ causative mutations are $R Y R 1$ and CACNA1S [69, 70]. MH may occur at any time during anaesthesia as well as in the early postoperative period [71]. Larach et al. found that increased temperature was among the first three early signs in $63.5 \%$ of $\mathrm{MH}$ reactions [72]. Hyperthermia can result in a temperature up to, or greater than, $44^{\circ} \mathrm{C}$ and lead to vital organ dys- function (heart failure, compartment syndrome, see below), and disseminated intravascular coagulation, which is the usual cause of death [73]. Experimental evidence suggests that the signs and symptoms of $\mathrm{MH}$ are associated with an uncontrolled release of intracellular $\mathrm{Ca}^{2+}$ from the skeletal muscle sarcoplasmic reticulum [74].

\section{Rhabdomyolysis in acquired diseases}

Acquired diseases which can cause RM are mainly endocrine disorders, various infections, muscle ischaemia and severe agitation. RM can be precipitated by electrolyte wasting, thyroid storm, increased sympathetic stimulation and metabolic demands forcing the body into hyper-metabolism [75-77].

\section{Endocrine disorders}

\section{Hypothyroidism}

Hypothyroidism may cause hypothyroid myopathy and rarely RM [75]. Clinical symptoms such as myalgias, proximal muscle weakness and cramps usually resolve after the normalization of thyroid hormones. The exact cause of RM in hypothyroidism is still not clarified. It is believed that impaired glycogenolysis, impaired mitochondrial oxidative metabolism or triglyceride turnover in thyroxine deficiency may be the responsible mechanisms [78-80]. Katipoglu et al. [81] describe a case of RM complicated by AKD in a patient who developed hypothyroidism after stopping l-thyroxine, which he was taking after undergoing total thyroidectomy for papillary thyroid cancer. The pathophysiology of AKD due to hypothyroidism may be explained by a decrease in cardiac output, which leads to reduced renal blood supply and the decrease of glomerular filtration rate (GFR) [80]. On the other hand, T3 (triiodothyronine) may directly affect systemic (including renal) vascular resistance. Moreover, brain natriuretic peptide (produced mainly from the ventricles in response to volume expansion, pressure overload, and elevated end diastolic pressure) levels have been found to be influenced by free T3 and T4 (thyroxine) [82, 83]. It has also been shown that $\mathrm{T} 4$ regulates $\mathrm{Na}^{+}$/ $\mathrm{Ca}^{2+}$ channels and $\mathrm{Na}^{+} / \mathrm{K}^{+}$-ATPase activity (see below) in the nephron sarcoplasmic reticulum [8486]. Of note, haemodialysis patients are likely to have an increased risk for hypothyroidism-induced RM due to the presence of comorbidities such as electrolyte imbalance, diabetes mellitus, and drug interactions (statins, antihypertensives, and antiarrhythmics) [86]. Another important mechanism of RM in hypothyroidism is the coexistence of statin therapy with potentially decreased drug catabolism, resulting in higher serum statin levels [87]. Also, amiodarone (a class III antiarrhythmic 
drug) may induce clinical hypothyroidism in approximately $5 \%$ of treated patients. Thus, hypothyroidism must be considered in the aetiological assessment of RM in these patients.

\section{Hyperthyroidism}

Hyperthyroidism may present as indolent proximal weakness, idiopathic ocular myositis or polymyositis [88, 89]. Painless thyroiditis is characterized by transient thyrotoxicosis lasting 2-4 weeks, followed by hypothyroidism for 1-3 months, and then resolution. Patients with painless thyroiditis usually do not require treatment during the hyperthyroid or hypothyroid phase because thyroid dysfunction is transient and rarely severe. However, if thyrotoxicosis leads to hypokalaemia, generalized muscle weakness (thyrotoxic periodic paralysis), RM and cardiac arrhythmias, including life-threatening ventricular tachycardia, may ensue [90]. The decreased potassium release from muscle cells due to hypokalaemia can decrease blood flow to muscles, leading to ischaemic RM [91]; see below. Chang et al. [92] describe a 61-year-old man with thyrotoxicosis, lower extremity paralysis and severe hypokalaemia. Despite attempts to correct potassium levels he developed pulseless polymorphic ventricular tachycardia (resuscitated with defibrillation), AKD and RM. The authors explain the cause of RM by 2 mechanisms, namely severe hypokalaemia and increased CK secondly to chest compressions and defibrillation. The release of CK after cardioversion indicates increased skeletal muscle damage and may predispose patients to RM [93-95]. Moreover, RM induced by hyperthyroidism may be present in individuals after exercise. Summachiwakij and Sachmechi describe RM in a patient with Graves disease induced by non-strenuous exercise [96].

\section{Hyper/hypoparathyroidism}

Hyperparathyroidism may cause muscle weakness (dropped head syndrome), muscle pain, or ischaemic, calcifying myopathy $[97,98]$.

Muscle involvement in hypoparathyroidism may present as myopathy, neuromyotonia, or RM. Sumnu et al. [99] describe the case of a 26-yearold epileptic male with leg myalgias, cramps, nausea, vomiting, and decreased urine output. He was admitted to the emergency department several times over 6 months and eventually diagnosed with primary hypoparathyroidism and AKD secondary to severe RM.

\section{Diabetes mellitus}

Diabetes is known to predispose to RM in patients with hyperosmolarity. Diabetes mellitus may cause diabetic myopathy [100-102] with a wide range of abnormalities, such as painless muscle wasting (diabetic amyotrophy), muscle inflammation, ischaemia, infarction, fibrosis, fatty atrophy, haemorrhage and diabetic myonecrosis, a self-limiting condition with acute onset of oedema and severely painful muscle necrosis. Usually, myonecrosis occurs in poorly controlled diabetes $[103,104]$. The development of RM in diabetic patients depends on the severity of serum hyperosmolarity and the presence of hypernatraemia $[77,105]$. Another mechanism which may provoke episodes of RM is through chronic kidney dysfunction, often present in diabetic patients, and comorbidities such as electrolyte imbalance and drug interactions (antihyperlipidemic, antihypertensives, and antiarrhythmics). Of note, hypolipidemic drugs (statin and/or fibrates), which many of these patients are taking, may provoke RM [106]. Antidiabetic drugs may also cause RM. Slim et al. report a case of a patient who developed severe RM after receiving pioglitazone [107] and Yokoyama et al. [108] report such a case after troglitazone. Potential risk factors identified in these cases include concomitant therapy with fibrate, alcohol abuse, and asymptomatic mild CK elevation prior to initiating therapy.

\section{Adrenal insufficiency}

$\mathrm{RM}$ is reported rarely in patients with acute adrenal insufficiency and may present as myopathy, hyperkalaemic neuromyopathy and hyponatraemia with sodium concentration reported as low as $97 \mathrm{mmol} / /$ [109]. Convulsions because of hyponatraemia can also cause muscle damage and a subsequent rise in CK. Lau and Yong describe a patient with acute primary adrenal insufficiency and severe hyponatraemia complicated by RM and AKD [110].

\section{Bacterial, viral and fungal infections}

Potentially all bacterial, viral and fungal infections can lead to RM [111-114]. Particularly, viral infections may cause various complications involving skeletal muscle, from non-specific myalgias to severe myositis and RM. Tanaka et al. [115] identified the influenza virus as an implicated agent in nearly $33 \%$ of known virus-induced RM. RM has been described in infections from Staphylococcus aureus, Mycoplasma pneumoniae, tuberculosis, tetanus, Salmonella, Brucella, Legionella and others [116-122]. Infectious conditions destroy muscle tissue by toxin production or direct bacterial invasion.

\section{Muscle ischaemia}

Conditions of generalized ischaemia and hypoxaemia, such as cardiogenic shock, CO poison- 
ing and status asthmaticus, are possible causes of RM, as they are associated with insufficient ATP production and sarcolemma dysfunction due to limited cellular oxygen delivery [123]. Localized compression, arterial thrombosis, prolonged vascular occlusion during surgical operations, air emboli and severe sickle cell crisis are other causes of RM. However, many events which eventually lead to RM due to muscle ischaemia occur during the reperfusion phase. After circulation is restored, large amounts of potentially toxic intracellular content are released into the bloodstream.

\section{Conditions with agitation}

Conditions with severe agitation, such as protracted myoclonic seizures in status epilepticus, delirium tremens, and the use of psychostimulant drugs may lead to RM [19, 42, 124, 125]. Severe agitation results in a state where ATP production cannot keep up with cellular demand, leading to depletion of energy supply and eventually cellular death.

The above listed causes of RM, and their relative prevalence, are summarised in Table I.

\section{Rhabdomyolysis pathology}

Independently of what causes RM, the consequences are the same. The increase in concentration of intracellular ionized calcium is the most harmful pathological process, is activated in RM and is critical for muscle cell survival. Muscle cell membrane damage allows leakage of intracellular ingredients (proteins, glycogen, carbonic anhydrase, CK, aldolase, lactate dehydrogenase and electrolytes) to extracellular fluid and thence the bloodstream. On the other hand, membrane damage permits the uncontrolled flow of calcium into the cytoplasm [126, 127].

\section{Proteins}

Myoglobin $(\mathrm{Mb})$ is the fundamental muscle cell protein and is composed of globin (a polypeptide chain of 153 amino acids) and of one molecule of haem. The Mb molecular weight is 18,800 daltons, one-fourth of haemoglobin [1, $9,128]$ and is present in both heart and in the skeletal muscles. The Mb concentration in these cells depends on the work performed by the tissue. For example, in people living at high altitude the concentration of $\mathrm{Mb}$ in the cells is increased. Also, in marine mammals $\mathrm{Mb}$ concentration is approximately 10 times higher than that of terrestrial mammals, giving them the ability to dive to great sea depths.

$\mathrm{Mb}$ is responsible for temporary oxygen storage [129] and correlates with cytochrome C oxidase expression, as well as capillary density $[130,131]$.
When muscle anoxia is present, $\mathrm{Mb}$ decreases the demand for glycolytic processes by releasing its oxygen content and allowing a continuance of much more efficient oxidative breakdown of lactate, pyruvate and similar metabolites. Plasma $\mathrm{Mb}$ concentration is around $0.003 \mathrm{mg} / \mathrm{dl}$. However, $\mathrm{Mb}$ may escape from damaged skeletal cells and bind to haptoglobin. Damage of more than $100 \mathrm{~g}$ of skeletal muscle leads to haptoglobin binding capacity saturation [129, 132-134] and circulating Mb becomes "free" to be filtered by the kidneys, where it acts directly on the nephrons, causing distal renal tubular necrosis. The half-life of $\mathrm{Mb}$ is

Table I. Causes and relative prevalence of non-traumatic, non-drug-induced rhabdomyolysis [11-125]

\begin{tabular}{|c|c|}
\hline Cause & Prevalence \\
\hline \multicolumn{2}{|l|}{ Genetic disorders: } \\
\hline \multicolumn{2}{|l|}{$\begin{array}{l}\text { Glycogen storage disease } \\
\text { (per live births) }\end{array}$} \\
\hline GSD-V McArdle disease & $1 / 100,000$ \\
\hline GDD-VII Tarui disease & $<1 / 1,000,000$ \\
\hline GSD-IX & $1 / 100,000$ \\
\hline GSD-X & $1 / 20,000-40,000$ \\
\hline GSD-XII & $1 / 20,000-43,000$ \\
\hline \multicolumn{2}{|l|}{ Other: } \\
\hline CTPII & $1-9 / 100,000$ \\
\hline Malignant hyperthermia & $1 / 5,000-50,000$ \\
\hline \multicolumn{2}{|l|}{ Mitochondrial myopathies: } \\
\hline MELAS syndrome & $1--9 / 1,000,000$ \\
\hline MERRF syndrome & $0.9 / 100,000$ \\
\hline KISS syndrome & Unclear; low \\
\hline CPEO & $1 / 30,000$ \\
\hline NARF & $1 / 36,000-40,000$ \\
\hline \multicolumn{2}{|l|}{ Muscular dystrophies: } \\
\hline DMD Duchenne & $1 / 3,500$ males \\
\hline BMD Becker & $1 / 18,000-31,000$ males \\
\hline \multicolumn{2}{|l|}{ Acquired diseases: } \\
\hline Hypo/hyperthyroidism & $4-5 \%$ \\
\hline Hypo/hyperparathyroidism & $25-66 / 100,000$ \\
\hline Diabetes mellitus & $8.6 \%$ \\
\hline Adrenal insufficiency & $4.4-6 / 1,000,000$ \\
\hline Infection & Up to $15 \%$ in sepsis \\
\hline Muscle ischaemia & $29.9 / 100,000$ \\
\hline Agitation & $8-15 \%$ in myoclonus \\
\hline
\end{tabular}


2-3 h. Following muscle injury, Mb serum concentration increases within $1-3 \mathrm{~h}$, peaks within 8-12 h, and then returns to normal concentration within $24 \mathrm{~h}$ [128]. Additionally, in RM increased levels of heavy-chain myosin fragments are observed and other proteases such as lactate dehydrogenase, aspartate aminotransferase (AST) and decreased levels of albumin (see below). In patients with RM, $\mathrm{Mb}$ concentration is not a diagnostic or prognostic criterion [134].

\section{Free oxygen radicals}

The increase in concentration of intracellular ionized calcium which occurs in RM may activate various vasoactive molecules and proteases, leading to the production of reactive oxygen species (ROS) [134]. The injured muscle cell is attacked by activated neutrophils, which increase the damage by releasing proteases and free radicals [135], resulting in an inflammatory, self-sustaining myolytic reaction rather than pure necrosis. These processes take place only after blood flow into the damaged tissue is restored.

\section{Glycogen}

The main muscle carbohydrate is glycogen. During RM blood glycogen levels may be raised and glycosuria may be present [136].

\section{Carbonic anhydrase III}

Carbonic anhydrase III (CA III) is a metalloenzyme found mainly in skeletal muscle, liver and adipose tissue. Its physiological role is to catalyze carbon dioxide and water to form bicarbonate and protons. CA III is considered as a biomarker of muscle ischaemia/necrosis [137, 138]. Lippi et al. [139] observed increased CA III levels in healthy men who performed $21-\mathrm{km}$ runs. Of note, the $M B$ myocardial isoenzyme of creatine phosphokinase (CK-MB, see below) is also higher as compared to pre-run levels.

\section{CK}

CK is an enzyme present in all types of muscle and its increased concentration in plasma is a marker of RM: after muscle damage, CK is released into the circulation $[93,140]$. The main function of $\mathrm{CK}$ is to catalyse the transportation of one phosphate group from creatinine to adenosine diphosphate (ADP), resulting in ATP [128, 141]. There are 3 CK isoenzymes: muscle-type (CK-MM), brain-type (CK-BB) and CK-MB. After muscle injury $C K$ is elevated within the first $12 \mathrm{~h}$, peaks within the first 3 days, and returns to baseline levels 3-5 days later [128, 141]. The increase of CK-MM concentration in some cas- es can reach even $100,000 \mathrm{IU} / \mathrm{ml}$ or more [128, 141]. Plasma CK elevation lasts longer than the $\mathrm{Mb}$ elevation ( $\mathrm{Mb}$ is rapidly metabolized by the liver; see above) $[128,141]$. Therefore, tests evaluating $\mathrm{Mb}$ concentration in plasma or urine are not very helpful.

\section{Calcium}

lonized calcium can be found in both extracellular and intracellular compartments of the human body. Its concentration in the extracellular space is significantly higher compared with the intracellular space ( 10,000 times higher). Major factors causing the shifting of ionized calcium from the extracellular to the intracellular space are either energy depletion in the muscle cell or rupture of the membrane's continuity (ionized calcium influx from the extracellular space into the cell due to its chemical gradient) $[127,142,143]$. The increased intracellular concentration of ionized calcium leads to overwork and overuse of the cell's energy. These two provoke increased sarcoplasmic influx of ionized sodium, chloride and water retention. The above result in cellular swelling and eventual destruction [144]. Ionized calcium further penetrates into the cell in exchange for ionized sodium to protect the increased intracellular sodium concentration [145]. Moreover, once muscle cells are injured, two major processes take place: 1) ATP leaks from cells causing ATPase pump dysfunction and further increase in ionized sodium, which activates the $2 \mathrm{Na}^{+} / \mathrm{Ca}^{2+}$ exchanger to correct ionic abnormalities $[123,128]$ and 2) the mitochondria release stored ionized calcium into the cytoplasm as a rescue measure [146]. All the above cause persistent contraction, ATP depletion, exhaustion and eventually cellular death.

\section{Potassium}

Muscle cells contain a significant amount of potassium and when disruption of the cell's membrane occurs its escape into the circulation results in hyperkalaemia: potassium levels higher than $8.5 \mathrm{mEq} / \mathrm{l}$ can cause cardiac arrhythmias (e.g. ventricular fibrillation) and sudden death] [91, 123, 128].

\section{Compartment syndrome}

On top of all the processes described above, the compartment syndrome may develop. As was already mentioned, failure of the transmembrane pump systems leads to muscle cell swelling. Then, intracompartmental pressure rises and may provoke additional damage and necrosis which due to anatomical particularities (non-communicating, closed systems) may require a fasciotomy [147149]. 


\section{Clinical and biochemical effects of rhabdomyolysis}

As was already mentioned, RM is a severe and potentially life-threatening condition. There are various clinical and biochemical consequences of RM induced by muscle cell damage, such as the following: 1) fluid overload in the affected $\operatorname{limb}(\mathrm{s})$, reaching even $10 \mathrm{l} / \mathrm{limb}$. This results in severe hypovolaemia and hypernatraemia, which may lead to hypovolaemic shock and/or acute renal failure [150]; 2) hyperalbuminaemia caused by hypovolaemia (later changes to hypoalbuminaemia due to inflammation, malnutrition, fluid overload); 3) acidosis provoked by lactic acid escape from the cells [151] which worsens hyperkalaemia and allows intratubular precipitation of $\mathrm{Mb}$ and uric acid; 4) severe hypocalcaemia due to release from the storage site and hyperphosphataemia, which may lead to cardiac arrhythmias, muscular contractions or seizures [152]; 5) release of nucleosides into the bloodstream (metabolized in the liver to purines, i.e. xanthine, hypoxanthine, and uric acid, which further stimulates tubular obstruction); 6) release of proteases into the bloodstream may cause hepatic dysfunction in $25 \%$ of patients with RM [153]; 7) acute kidney injury (AKI, see below); and 8) disseminated intravascular coagulation as a result of the activation of the coagulation cascade by components released from damaged muscles, which may be responsible for haemorrhagic complications.

\section{RM-induced AKI}

The pathophysiology of RM-induced AKI is believed to be caused mainly by 3 mechanisms: renal vasoconstriction, intratubular cast formation, and $M b$ toxicity [154, 155].

Reduced renal blood flow causes renal vasoconstriction and secondary activation of the renin-angiotensin-aldosterone system. Also, the decrease in renal blood flow promotes cast formation. On the other hand, $M b$ and its breakdown compounds such as iron exert direct a cytotoxic effect on the nephron [142]. Additionally, iron in the Mb oxidizes lipid membrane components and causes lipid peroxidation, called redox cycling [142]. The presence of metabolic acidosis promotes cast formation, tubular obstruction and pronounced $\mathrm{Mb}$ nephrotoxicity [156].

\section{Rhabdomyolysis management}

Management of RM is presently based on observations from retrospective studies, case reports, and case series which describe various RM treatments, particularly for AKI complications. The most significant intervention in RM, which may save the life of the patient, is to preserve diuresis by considerable hydration, use of mannitol, urine alkalization and forced diuresis [86, 157]. Immediate fluid resuscitation to restore and preserve renal perfusion and increase urine flow rate [132] is critical. Potassium or lactate-containing solutions should be avoided because of the risk of RM-associated hyperkalaemia and lactic acidosis [133]. Urine alkalinisation with sodium bicarbonate (not needed in patients with good urinary response) is helpful for decreasing cast formation, diminishing the nephrotoxic effects of $\mathrm{Mb}$, inhibiting lipid peroxidation, and decreasing the risk of hyperkalaemia [133, 146, 158]. Hyperkalaemia treatment should be initiated with IV insulin, glucose and calcium. In some cases, dialysis may be an option. Hypercalcaemia responds to saline diuresis and IV furosemide $[133,146]$. In cases with RM-induced hyperphosphataemia greater than $7 \mathrm{mg} / \mathrm{dl}$ oral phosphate binders may be administered. Hypophosphataemia, which may occur late in RM, requires treatment only when the serum level is below $1 \mathrm{mg} / \mathrm{dl}$ [150]. Dialysis should be considered as a lifesaving procedure for patients with severely elevated serum potassium, persistent acidosis, or oliguric AKI with fluid overload [158]. For the better management of renal replacement therapy in RM-induced AKI see Guidelines of Kidney Disease Improving Global Outcomes (KDIGO Clinical Practice Guideline for Acute Kidney Injury. [http:// www.kidney-international.org).

\section{Conclusions}

Rhabdomyolysis is a severe and potentially life-threatening condition, fortunately presenting infrequently. Early identification is key to timely treatment. Recognizing underlying abnormalities, particularly genetic disorders, is a diagnostic challenge. Familiarity with RM pathophysiology leads to its better management, particularly for renal replacement interventions in RM-induced AKI.

\section{Conflict of interest}

The authors declare no conflict of interest.

\section{References}

1. Kaufman RP, Barry PE. Rhabdomyolysis with myoglobinuria: report of a case. N Engl J Med 1959; 260: 430-2.

2. Rutecki GW, Ognibene AJ, Geib JD. Rhabdomyolysis in antiquity: from ancient descriptions to scientific explanation. Pharos 1998; 61: 18-22.

3. KolovouV, Bilianou H, Kolovou G. Safe use of statins: focus on muscle toxicity. Clin Lipidol 2016; 20: 1-7.

4. Cervellin G, Comelli I, Benatti M, Sanchis-Gomar F, Bassi A, Lippi G. Non-traumatic rhabdomyolysis: background, laboratory features, and acute clinical management. Clin Biochem 2017; 50: 656-62.

5. Zutt R, van der Kooi AJ, Linthorst GE, Wanders RJ, de Visser M. Rhabdomyolysis: review of the literature. Neuromuscul Disord 2014; 24: 651-9. 
6. Bosch X, Poch E, Grau JM. Rhabdomyolysis and acute kidney injury. N Engl J Med 2009; 361: 62-72.

7. Chatzizisis YS, Misirli G, Hatzitolios Al, Giannoglou GD. The syndrome of rhabdomyolysis: complications and treatment. Eur J Intern Med 2008; 19: 568-74.

8. Rodríguez-Capote K, Balion CM, Hill SA, Cleve R, Yang L, El Sharif. A utility of urine myoglobin for the prediction of acute renal failure in patients with suspected rhabdomyolysis: a systematic review. Clin Chem 2009; 55: 2190-7.

9. Zorova LD, Pevzner IB, Chupyrkina AA, et al. The role of myoglobin degradation in nephrotoxicity after rhabdomyolysis. Chem Biol Interact 2016; 256: 64-70.

10. Knottnerus SJG, Bleeker JC, Wüst RCI, et al. Disorders of mitochondrial long-chain fatty acid oxidation and the carnitine shuttle. Rev Endocr Metab Disord 2018; 19: 93-106.

11. Bhattacharya K. Investigation and management of the hepatic glycogen storage diseases. Transl Pediatr 2015; 4: 240-8.

12. Quinlivan R, Buckley J, James M, et al. McArdle disease: a clinical review. J Neurol Neurosurg Psychiatry 2010; 81:1182-8

13. Pérez M, Ruiz JR, Fernández Del Valle $M$, et al. The second wind phenomenon in very young McArdle's patients. Neuromuscul Disord 2009; 19: 403-5.

14. Godfrey R, Quinlivan R. Skeletal muscle disorders of glycogenolysis and glycolysis. Nat Rev Neurol 2016; 12: 393-402.

15. Nogales-Gadea G, Arenas J, Andreu AL. Molecular genetics of McArdle's disease. Curr Neurol Neurosci Rep 2007; 7: 84-92

16. De Stephano N, Argov Z, Matthews PM, Karpati G, Arnold DL. Impairment of muscle mitochondrial oxidative metabolism in McArdle's disease. Muscle Nerve 1996; 19: 764-9.

17. Dorin RI, Field JC, Boyle PJ, Eaton RP, Icenogle MV. Insulin resistance limits glucose utilisation and exercise tolerance in myophosphorylase deficiency and NIDDM. J Appl Physiol 1996; 81: 1273-8.

18. Haller RG, Clausen T, Vissing J. Reduced levels of skeletalmuscle $\mathrm{Na} \pm \mathrm{K} \pm$-ATPase in McArdle disease. Neurology 1998; 50: 37-40.

19. Park HJ, Chang Y, Lee JE, et al. Recurrent episodes of rhabdomyolysis after seizures in a patient with glycogen storage disease type V. J Clin Neurol 2016; 12: 373-5.

20. Brady S, Godfrey R, Scalco RS, Quinlivan R. Emotionally-intense situations can result in rhabdomyolysis in McArdle disease. BMJ Case Rep 2014; 2014: pii: bcr2013203272.

21. Lucia A, Nogales-Gadea G, Pérez M, Martín MA, Andreu AL, Arenas J. McArdle disease: what do neurologists need to know? Nat Clin Pract Neurol 2008; 4: 568-77.

22. Aasly J, van Diggelen OP, Boer AM, Brønstad G. Phosphoglycerate kinase deficiency in two brothers with McArdle-like clinical symptoms. Eur J Neurol 2000; 7: 111-3.

23. Nakajima H, Raben N, Hamaguchi T, Yamasaki T. Phosphofructokinase deficiency; past, present and future. Curr Mol Med 2002; 2: 197-212.

24. DiMauro S, Lamperti C. Muscle glycogenoses. Muscle Nerve 2001; 24: 984-99.

25. Musumeci O, Bruno C, Mongini T, et al. Clinical features and new molecular findings in muscle phosphofructokinase deficiency (GSD type VII). Neuromuscul Disord 2012; 22: 325-30.
26. Choi R, Park HD, Kang B, et al. PHKA2 mutation spectrum in Korean patients with glycogen storage disease type IX: prevalence of deletion mutations. BMC Med Genet 2016; 17: 33.

27. Ørngreen MC, Schelhaas HJ, Jeppesen TD, et al. Is muscle glycogenolysis impaired in X-linked phosphorylase b kinase deficiency? Neurology 2008; 70: 1876-82.

28. Naini A, Toscano A, Musumeci O, Vissing J, Akman HO, DiMauro S. Muscle phosphoglycerate mutase deficiency revisited. Arch Neurol 2009; 66: 394-8.

29. Oh SJ, Park KS, Ryan Jr HF, et al. Exercise-induced cramp, myoglobinuria, and tubular aggregates in phosphoglycerate mutase deficiency. Muscle Nerve 2006; 34: 572-6.

30. Tonin P, Bruno C, Cassandrini D, et al. Unusual presentation of phosphoglycerate mutase deficiency due to two different mutations in PGAM-M gene. Neuromuscul Disord 2009; 19: 776-8.

31. Vissing J, Quistorff B, Haller RG. Effect of fuels on exercise capacity in muscle phosphoglycerate mutase deficiency. Arch Neurol 2005; 62: 1440-3.

32. Kreuder J, Borkhardt A, Repp R, et al. Brief report: inherited metabolic myopathy and hemolysis due to a mutation in aldolase A. N Engl J Med 1996; 334: 1100-4.

33. Yao DC, Tolan DR, Murray MF, et al. Hemolytic anemia and severe rhabdomyolysis caused by compound heterozygous mutations of the gene for erythrocyte/muscle isozyme of aldolase, ALDOA(Arg303X/Cys338Tyr). Blood 2004; 103: 2401-3.

34. Mamoune A, Bahuau M, Hamel Y, et al. A thermolabile aldolase a mutant causes fever-induced recurrent rhabdomyolysis without hemolytic anemia. PLoS Genet 2014; 10: e1004711.

35. Hamel Y, Mamoune A, Mauvais FX, et al. Acute rhabdomyolysis and inflammation. J Inherit Metab Dis 2015; 38: 621-8.

36. Kopp A, Bistrian BR. Inherited metabolic myopathy and hemolysis due to a mutation in aldolase A. N Engl J Med 1996; 335: 1242-3.

37. Bahreini F, Houshmand M, Modarressi MH, Akrami SM. Mitochondrial variants in pompe disease: a comparison between classic and non-classic forms. Cell J 2018; 20: 333-9.

38. Finsterer J. Rhabdomyolysis in MELAS may be multifactorial. Rinsho Shinkeigaku 2017; 57: 399.

39. Witherspoon JW, Vasavada RP, Waite MR, et al. 6-minute walk test as a measure of disease progression and fatigability in a cohort of individuals with RYR1-related myopathies. Orphanet J Rare Dis 2018; 13: 105.

40. Ahuja AS. Understanding mitochondrial myopathies: a review. Peer 2018; 6: e4790.

41. Finsterer J, Zarrouk-Mahjoub S, Shoffner JM. MERRF classification: implications for diagnosis and clinical trials. Pediatr Neurol 2018; 80: 8-23.

42. Finsterer J, Zarrouk-Mahjoub S. Management of epilepsy in MERRF syndrome. Seizure 2017; 50: 166-70.

43. Finsterer J, Zarrouk-Mahjoub S. Kearns-Sayre syndrome is genetically and phenotypically heterogeneous. Pediatr Med Chir 2018; 40. doi: 10.4081/pmc.2018.193.

44. Chatzistefanou KI, Brouzas D, Asproudis I, Tsina E, Droutsas KD, Koutsandrea C. Strabismus surgery for diplopia in chronic progressive external ophthalmoplegia. Int Ophthalmol 2019; 39: 213-7.

45. Mordel P, Schaeffer S, Dupas Q, et al. A 2 bp deletion in the mitochondrial ATP 6 gene responsible for the NARP (neuropathy, ataxia, and retinitis pigmentosa) 
syndrome. Biochem Biophys Res Commun 2017; 494: 133-7.

46. Claeys KG, Abicht A, Häusler M, et al. Novel genetic and neuropathological insights in neurogenic muscle weakness, ataxia, and retinitis pigmentosa (NARP). Muscle Nerve 2016; 54: 328-33.

47. Wang W, Zhuang Q, Ji K, et al. Identification of miRNA, IncRNA and mRNA-associated ceRNA networks and potential biomarker for MELAS with mitochondrial DNA A3243G mutation. Sci Rep 2017; 7: 41639.

48. Mukai M, Nagata E, Mizuma A, et al. Adult-onset mitochondrial myopathy, encephalopathy, lactic acidosis, and stroke (MELAS)-like encephalopathy diagnosed based on the complete sequencing of mitochondrial DNA extracted from biopsied muscle without any myopathic changes. Intern Med 2017; 56: 95-9.

49. Koenigsberg HW. Manic pseudodementia: case report. J Clin Psychiatry 1984; 45: 132-4.

50. Pavlakis SG, Phillips PC, DiMauro S, De Vivo DC, Rowland LP. Mitochondrial myopathy, encephalopathy, lactic acidosis, and stroke like episodes: a distinctive clinical syndrome. Ann Neurol 1984; 16: 481-8.

51. Holt IJ, Harding AE, Petty RK, Morgan-Hughes JA. A new mitochondrial disease associated with mitochondrial DNA heteroplasmy. Am J Hum Genet 1990; 46: 428-33.

52. Mah JK. Current and emerging treatment strategies for Duchenne muscular dystrophy. Neuropsychiatr Dis Treat 2016; 12: 1795-807.

53. Mavrogeni S, Markousis-Mavrogenis G, Papavasiliou A, Papadopoulos G, Kolovou G. Cardiac involvement in duchenne muscular dystrophy and related dystrophinopathies. Methods Mol Biol 2018; 1687: 31-42.

54. Mavrogeni S, Markousis-Mavrogenis G, Papavasiliou A, Kolovou G. Cardiac involvement in Duchenne and Becker muscular dystrophy. World J Cardiol 2015; 7: 410-4.

55. Kieny P, Chollet S, Delalande P, et al. Evolution of life expectancy of patients with Duchenne muscular dystrophy at AFM Yolaine de Kepper Centre between 1981 and 2011. Ann Phys Rehabil Med 2013; 56: 443-54.

56. Mavrogeni S, Giannakopoulou A, Papavasiliou A, et al. Cardiac profile of asymptomatic children with Becker and Duchenne muscular dystrophy under treatment with steroids and with/without perindopril. BMC Cardiovasc Disord 2017; 17: 197.

57. Emery AE. Population frequencies of inherited neuromuscular diseases-a world survey. Neuromuscul Disord 1991; 1: 19-29.

58. Mah JK, Korngut L, Dykeman J, Day L, Pringsheim T, Jette N. A systematic review and meta-analysis on the epidemiology of Duchenne and Becker muscular dystrophy. Neuromuscul Disord 2014; 24: 482-91.

59. Mavrogeni S, Pons R, Nikas I, et al. Brain and heart magnetic resonance imaging/spectroscopy in duchenne muscular dystrophy. Eur J Clin Invest 2017; 47: doi: 10.1111/eci.12842.

60. Muntoni F, Torelli S, Ferlini A. Dystrophin and mutations: one gene, several proteins, multiple phenotypes. Lancet Neurol 2003; 2: 731-40.

61. Wallace GQ, McNally EM. Mechanisms of muscle degeneration, regeneration, and repair in the muscular dystrophies. Annu Rev Physiol 2009; 71: 37-57.

62. Wieser T, Deschauer M, Olek K, Hermann T, Zierz S. Carnitine palmitoyltransferase II deficiency: molecular and biochemical analysis of 32 patients. Neurology 2003; 60: 1351-3.

63. Cucchiari D, Colombo I, Amato O, et al. Exertional rhabdomyolysis leading to acute kidney injury: when ge- netic defects are diagnosed in adult life. CEN Case Rep 2018; 7: 62-5.

64. Balasubramanian M, Jenkins TM, Kirk RJ, et al. Recurrent rhabdomyolysis caused by carnitine palmitoyltransferase II deficiency, common but under-recognised: lessons to be learnt. Mol Genet Metab Rep 2018; 15: 69-70.

65. Gjorgjievski N, Dzekova-Vidimliski P, Petronijevic Z, et al. Carnitine palmitoyltransferase II deficiency (CPT II) followed by rhabdomyolysis and acute kidney injury. Open Access Maced J Med Sci 2018; 6: 666-8.

66. Otsuki S, Yasuda T, Mukaida K, et al. Myotoxicity of local anesthetics is equivalent in individuals with and without predisposition to malignant hyperthermia. J Anesth 201; 32: 616-23.

67. Smith JL, Tranovich MA, Ebraheim NA. A comprehensive review of malignant hyperthermia: preventing further fatalities in orthopedic surgery. J Orthop 2018; 15: 578-80.

68. Neira VM, Al Madhoun W, Ghaffari K, Barrowman N, Berrigan P, Splinter W. Efficacy of malignant hyperthermia association of the united states-recommended methods of preparation for malignant hyperthermia-susceptible patients using Dräger Zeus Anesthesia Workstations and associated costs. Anesth Analg 2019; 129; 74-83.

69. Jia Y, Chang HC, Schipma MJ, et al. Cardiomyocyte-specific ablation of Med1 subunit of the mediator complex causes lethal dilated cardiomyopathy in mice. PLoS One 2016; 11: e0164316.

70. Schiemann AH, Stowell KM. Comparison of pathogenicity prediction tools on missense variants in RYR1 and CACNA1S associated with malignant hyperthermia. Br J Anaesth 2016; 117: 124-8.

71. Litman RS, Flood CD, Kaplan RF, Kim YL, Tobin JR. Postoperative malignant hyperthermia: an analysis of cases from the North American Malignant Hyperthermia Registry. Anesthesiology 2008; 109: 825-9.

72. Larach MG, Allen GC, Brandom BW, Lehman EB. Temperature changes are not late signs of malignant hyperthermia: a NAMH Registry of MHAUS study. Anesthesiology 2008; 109: A374.

73. Nelson TE. Porcine malignant hyperthermia: critical temperatures for in vivo and in vitro responses. Anesthesiology 1990; 73: 449-54.

74. Jiang D, Chen W, Xiao J, et al. Reduced threshold for luminal Ca2+ activation of RyR1 underlies a causal mechanism of porcine malignant hyperthermia. J Biol Chem 2008; 283: 20813-20.

75. Salehi N, Agoston E, Munir I, Thompson GJ. Rhabdomyolysis in a patient with severe hypothyroidism. Am J Case Rep 2017; 18: 912-8.

76. Finsterer J, Löscher WN, Wanschitz J, Quasthoff S, Grisold W. Secondary myopathy due to systemic diseases. Acta Neurol Scand 2016; 134: 388-402.

77. Shah SK, Shah L, Bhattarai S, Giri M. Rhabdomyolysis due to severe hypophosphatemia in diabetic ketoacidosis. JNMA J Nepal Med Assoc 2015; 53: 137-40.

78. Altay M, Duranay M, Ceri M. Rhabdomyolysis due to hypothyroidism. Nephrol Dial Transplant 2005; 20: 847-8.

79. Barahona MJ, Mauri A, Sucunza N, Paredes R, Wagner AM. Hypothyroidism as a cause of rhabdomyolysis. Endocrine J 2002; 49: 621-3.

80. Monzani F, Caraccio N, Manca L, Murri L, Ferrannini E. Clinical and biochemical features of muscle dysfunction in subclinical hypothyroidism. J Clin Endocrinol Metab 1997; 82: 3315-8. 
81. Katipoglu B, Ates I, Acehan F, Meteris A, Yılmaz N. Rhabdomyolysis case based on hypothyroidism. Endocrinol Diabetes Metab Case Rep 2016; 36: 1723.e1-6.

82. Kato K, Murakami H, Isozaki O, Tsushima T, Takano K. Serum concentrations of BNP and ANP in patients with thyrotoxicosis. Endocrinol J 2009; 56: 17-27.

83. Schultz M, Faber J, Kistorp C, et al. N-terminal-pro-Btype natriuretic peptide (NT-pro-BNP) in different thyroid function states. Clin Endocrinol 2004; 60: 54-9.

84. McDonough AA, Brown TA, Horowitz B, et al. Thyroid hormone coordinately regulates $\mathrm{Na}+\mathrm{K}+-\mathrm{ATPase}$ alphaand beta-subunit mRNA levels in kidney. Am J Physiol 1988; 254: C323-9.

85. Cai Y, Tang L. Rare acute kidney injury secondary to hypothyroidism-induced rhabdomyolysis. Yonsei Med J 2013; 54: 172-6.

86. Huerta-Alardín AL, Varon J, Marik PE. Bench-to-bedside review: rhabdomyolysis - an overview for clinicians. Crit Care 2005; 9: 158-69.

87. Kolovou CL, Jbara Y, Bricker D. Rhabdomyolysis in the setting of induced hypothyroidism and statin therapy: a case report. Eur Thyroid J 2015; 4: 62-4.

88. Achibana S, Yokoi T, Sato S, Oda Y, Yanase T, Yamashita $H$. Idiopathic orbital myositis associated with Graves' disease. Intern Med 2013; 52: 787-90.

89. Hardiman O, Molloy F, Brett F, Farrell M. Inflammatory myopathy in thyrotoxicosis. Neurology 1997; 48: 339-41.

90. Nadkarni PJ, Sharma M, Zinsmeister B, Wartofsky L, Burman KD. Thyrotoxicosis-induced ventricular arrhythmias. Thyroid 2008; 18: 1111-4.

91. Knochel JP, Schlein EM. On the mechanism of rhabdomyolysis in potassium depletion. J Clin Invest 1972; 51: 1750-8.

92. Chang KY, Lee SH, Park HS, Ko SH, Ahn YB, Kim HW. Severe hypokalemia and thyrotoxic paralysis from painless thyroiditis complicated by life-threatening polymorphic ventricular tachycardia and rhabdomyolysis. Intern Med 2014; 53: 1805-8.

93. O’Neill PG, Faitelson L, Taylor A, Puleo P, Roberts R, Pacifico A. Time course of creatine kinase release after termination of sustained ventricular dysrhythmias. Am Heart J 1991; 122: 709-14.

94. Jakobsson J, Odmansson I, Nordlander R. Enzyme release after elective cardioversion. Eur Heart J 1990; 11: 749-52.

95. Minor RL Jr, Chandran PK, Williams CL. Rhabdomyolysis and myoglobinuric renal failure following cardioversion and CPR for acute MI. Chest 1990; 97: 485-6.

96. Summachiwakij S, Sachmechi I. Rhabdomyolysis induced by nonstrenuous exercise in a patient with Graves' disease. Case Rep Endocrinol 2014; 2014: 286450.

97. Walker RP, Palouan E, Gopalsami C. Symptoms in patients with primary hyperparathyroidism: muscle weakness or sleepiness. Endocr Pract 2004; 10: 404-8.

98. Thage O. Metabolic neuropathies and myopathies in adults. Clinical aspects. Acta Neurol Scand 1970; 46 (Suppl 43): 120.

99. Sumnu A, Aydin Z, Gursu M, et al. A case of primary hypoparathyroidism presenting with acute kidney injury secondary to rhabdomyolysis. Case Rep Nephrol 2016; 2016: 3240131.

100. Huang BK, Monu JU, Doumanian J. Diabetic myopathy: MRI patterns and current trends. AJR Am J Roentgenol 2010; 195: 198-204.

101. Su Z, Robinson A, Hu L, et al. Acupuncture plus low-frequency electrical stimulation (Acu-LFES) Attenuates diabetic myopathy by enhancing muscle regeneration. PLoS One 2015; 10: e0134511.

102. D'Souza DM, Al-Sajee D, Hawke TJ. Diabetic myopathy: impact of diabetes mellitus on skeletal muscle progenitor cells. Front Physiol 2013; 4: 379.

103. Mazoch MJ, Bajaj G, Nicholas R, et al. Diabetic myonecrosis: likely an underrecognized entity. Orthopedics 2014; 37: e936-9.

104. Chalasani S, Bettadahalli SS, Bhupathi SV, Aswani VH. A novel case of diabetic muscle necrosis in a patient with cystic fibrosis-related diabetes. Clin Med Res 2013; 11: 113-6.

105. Lord GM, Scott J, Pusey CD, et al. Diabetes and rhabdomyolysis. A rare complication of a common disease. BMJ 1993; 307: 1126-8.

106. Soyoral YU, Canbaz ET, Erdur MF, Emre H, Begenik H, Erkoc R. Fenofibrate - induced rhabdomyolysis in a patient with stage 4 chronic renal failure due to diabetes mellitus. J Pak Med Assoc 2012; 62: 849-51.

107. Slim R, Ben Salem C, Zamy M, Biour M. Pioglitazone-induced acute rhabdomyolysis. Diabetes Care 2009; 32: e84.

108. Yokoyama M, Izumiya Y, Yoshizawa M, Usuda R. Acute rhabdomyolysis associated with troglitazone. Diabetes Care 2000; 23: 421-2.

109. Egan JJ, Davies AJ, Jones MK. Hyponatraemic rhabdomyolysis in Addison's disease. Postgrad Med J 1994 70: 830-2.

110. Lau SY, Yong TY. Rhabdomyolysis in acute primary adrenal insufficiency complicated by severe hyponatraemia. Intern Med 2012; 51: 2371-4.

111. Hamid A, Dhrolia MF, Qureshi R, Imtiaz S, Ahmad A. Acute kidney injury secondary to rhabdomyolysis: a rare presentation of chikungunya fever. J Coll Physicians Surg Pak 2018; 28: S94-6.

112. Attanasi M, Petrosino MI, Guidone PI, et al. A pediatric case of rhabdomyolysis with acute renal failure due to co-infection with Epstein-Barr virus and Human herpesvirus 6. Arch Med Sci 2018; 14: 254-6.

113. Nicastri E, Brucato A, Petrosillo N, Biava G, Uyeki TM, Ippolito G; INMI's Ebola Team. Acute rhabdomyolysis and delayed pericardial effusion in an Italian patient with Ebola virus disease: a case report. BMC Infect Dis 2017; 17: 597.

114. Bhargava R, Abohashem Aly AA, Mertz JI, Mustafa R. Rhabdomyolysis as the first manifestation of human immunodeficiency virus infection. CEN Case Rep 2016; 5: 48-50.

115. Tanaka T, Takada T, Takagi D, Takeyama N, Kitazawa Y. Acute renal failure due to rhabdomyolysis associated with echovirus 9 infection: a case report and review of literature. Jpn J Med 1989; 28: 237-42.

116. Ravry C, Fedou AL, Dubos M, et al. Severe rhabdomyolysis associated with staphylococcus aureus acute endocarditis requiring surgery. Surg Infect (Larchmt) 2015; 16: 840-2.

117. Al Shamkhani W, Ajaz Y, Saeed Jafar N, Roy Narayanan S. Myocarditis and rhabdomyolysis in a healthy young man caused by salmonella gastroenteritis. Case Rep Infect Dis 2015; 2015: 954905.

118. Naha K, Karanth S, Dasari S, Prabhu M. Polymyositislike syndrome with rhabdomyolysis in association with brucellosis. Asian Pac J Trop Med 2012; 5: 755-6.

119. Attanasi M, Petrosino MI, Guidone PI, et al. A pediatric case of rhabdomyolysis with acute renal failure due to co-infection with Epstein-Barr virus and Human herpesvirus 6. Arch Med Sci 2018; 14: 254-6. 
120. Tedesco A, Guglielmetti L, Conti M, Cazzadori A, Concia E. Pulmonary tuberculosis mimicking a severe community-acquired pneumonia with rhabdomyolysis. Infez Med 2013; 21: 146-8.

121. El Koraichi A, Aggoug B, Tadili J, Benjelloun MY, El Haddoury M, El Kettani SE. Severe tetanus complicated with rhabdomyolysis and acute renal failure: a pediatric case report. Arch Pediatr 2012; 19: 726-8.

122. Shimura C, Saraya T, Wada H, et al. Pathological evidence of rhabdomyolysis-induced acute tubulointerstitial nephritis accompanying Legionella pneumophila pneumonia. J Clin Pathol 2008; 61: 1062-3.

123. Criddle L. Rhabdomyolysis. Pathophysiology, recognition, and management. Crit Care Nurse 2003; 23: 14-32.

124. Adedinsewo DA, Odewole O, Todd T. Acute rhabdomyolysis following synthetic cannabinoid ingestion. N Am J Med Sci 2016; 8: 256-8.

125. Rajapakse S, Abeynaike L, Wickramarathne T. Venlafaxine-associated serotonin syndrome causing severe rhabdomyolysis and acute renal failure in a patient with idiopathic Parkinson disease. J Clin Psychopharmacol 2010; 30: 620-2.

126. Hadjis T, Grieff M, Lockhat D, Kaye M. Calcium metabolism in acute renal failure due to rhabdomyolysis. Clin Nephrol 1993; 39: 22-7.

127. Momma K, Homma T, Isaka R, Sudevan S, Higashitani A. Heat-induced calcium leakage causes mitochondrial damage in caenorhabditis elegans body-wall muscles. Genetics 2017; 206: 1985-94.

128. Zhang MH. Rhabdomyolosis and its pathogenesis. World J Emerg Med 2012; 3: 11-5.

129. Vanholder R, Sever MS, Erek E, Lameire N. Rhabdomyolysis. J Am Soc Nephrol 2000; 11: 1553-61.

130. Lawrie RA. The relation of energy-rich phosphate in muscle to myoglobin and to cytochrome-oxidase activity. Biochem J 1953; 55: 305-9.

131. Reis DJ, Wooten GF. The relationship of blood flow to myoglobin, capillary density, and twitch characteristics in red and white skeletal muscle in cat. J Physiol 1970; 210: 121-35.

132. Zimmerman JL, Shen MC. Rhabdomyolysis. Chest 2013; 144: 1058-65.

133. Khan FY. Rhabdomyolysis: a review of the literature. Neth J Med 2009; 67: 272-83.

134. Servonnet A, Dubost C, Martin G, et al. Myoglobin: still a useful biomarker in 2017? Ann Biol Clin 2018; 76: 37-41

135. Slater MS, Mullins RJ. Rhabdomyolysis and myoglobinuric renal failure in trauma and surgical patients: a review. J Am Coll Surg 1998; 186: 693-716.

136. Nance JR, Mammen AL. Diagnostic evaluation of rhabdomyolysis. Muscle Nerve 2015; 51: 793-810.

137. Lindskog S. Structure and mechanism of carbonic anhydrase. Pharmacol Ther 1997; 74: 1-20.

138. Lippi G, Cervellin G, Schena F. How much myocardium mass may be injured during endurance physical exercise? Clin Chim Acta 2017; 470: 29-30.

139. Lippi G, Schena F, Montagnana M, Salvagno GL, Guidi GC. Influence of acute physical exercise on emerging muscular biomarkers. Clin Chem Lab Med 2008; 46: 1313-8.

140. Vanholder R, Zutt R, van der Kooi AJ, Linthorst GE, Wanders RJ, de Visser M. Rhabdomyolysis: review of the literature. Neuromuscul Disord 2014; 24: 651-9.

141. Schlattner U, Tokarska-Schlattner M, Wallimann T. Mitochondrial creatine kinase in human health and disease. Biochim Biophys Acta 2006; 1762: 164-80.
142. Boutaud O, Roberts LJ. Mechanism-based therapeutic approaches to rhabdomyolysis-induced renal failure. Free Radic Biol Med 2011; 51: 1062-7.

143. Safari S, Eshaghzade M, Najafi I, et al. Trends of serum electrolyte changes in Crush syndrome patients of Bam Earthquake: a cross sectional study. Emerg (Tehran) 2017; 5: e7.

144. Poels PJ, Gabreëls FJ. Rhabdomyolysis: a review of the literature. Clin Neurol Neurosurg 1993; 95: 175-92.

145. Brumback RA, Feeback DL, Leech RW. Rhabdomyolysis in childhood: a primer on normal muscle function and selected metabolic myopathies characterized by disordered energy production. Pediatr Clin North Am 1992; 39: 821-58.

146. Torres PA, Helmestetter JA, Kaye AM, Kaye AD. Rhabdomyolysis: pathogenesis, diagnosis, and treatment. Ochsner J 2015; 15: 58-69.

147. Better OS, Stein JH. Early management of shock and prophylaxis of acute renal failure in traumatic rhabdomyolysis. N Engl J Med 1990; 322: 825-9.

148. Ho CWG, Yang SH, Wong CH, Chong SJ. High-voltage electrical injury complicated by compartment syndrome and acute kidney injury with successful limb salvage: a case report and review of the literature. Int J Surg Case Rep 2018; 48: 38-42.

149. Mehta V, Chowdhary V, Lin C, Jbara M, Hanna S. Compartment syndrome of the hand: a case report and review of literature. Radiol Case Rep 2017; 13: 212-5.

150. Sauret JM, Marinides G, Wang GK. Rhabdomyolysis. Am Fam Physician 2002; 65: 907-12.

151. Gabow PA, Kaehny WD, Kelleher SP. The spectrum of rhabdomyolysis. Medicine 1982; 61: 141-52.

152. Lane JT, Boudreau RJ, Kinlaw WB. Disappearance of muscular calcium deposits during resolution of prolonged rhabdomyolysis-induced hypercalcemia. Am J Med 1990; 89: 523-5.

153. Akmal M, Massry SG. Reversible hepatic dysfunction associated with rhabdomyolysis. Am J Nephrol 1990; 10: 49-52.

154. Zager RA, Johnson AC, Becker K. Plasma and urinary heme oxygenase-1 in AKI. J Am Soc Nephrol 2012; 23: 1048-57.

155. Moore KP, Holt SG, Patel RP, et al. A causative role for redox cycling of myoglobin and its inhibition by alkalinization in the pathogenesis and treatment of rhabdomyolysis-induced renal failure. J Biol Chem 1998; 273: 31731-7.

156. Bagley WH, Yang H, Shah KH. Rhabdomyolysis. Intern Emerg Med 2007; 2: 210-8.

157. Malik GH. Rhabdomyolysis and myoglobin-induced acute renal failure. Saudi J Kidney Dis Transpl 1998; 9: 273-84.

158. Petejova N, Martinek A. Acute kidney injury due to rhabdomyolysis and renal replacement therapy: a critical review. Crit Care 2014; 18: 224. 